\title{
Improving internal erosion resistance of silty sand using additives
}

Seyed Mohammad Ali Zomorodian PhD

Associate Professor, Department of Water Engineering,

Shiraz University, Shiraz, Iran (corresponding author:

mzomorod@shirazu.ac.ir)

Shabnam Moghispoor MSC

Former postgraduate student, Department of Water Engineering,

Shiraz University, Shiraz, Iran

\author{
Brendan C. O'Kelly PhD, FTCD, CEng, CEnv, MICE \\ Associate Professor, Department of Civil, Structural and \\ Environmental Engineering, Trinity College Dublin, Dublin, Ireland \\ (corresponding author: bokelly@tcd.ie) (Orcid:0000-0002-1343-4428) \\ Shaghayegh Sadat Babaei MSc \\ Former postgraduate student, Department of Water Engineering, \\ Shiraz University, Shiraz, Iran
}

Seepage-induced erosion, leading to piping, is one of the most common causes of failure for earth dykes, levees and dams. Various soil improvement (mixing) technologies can be employed to improve the internal erosion resistance of more troublesome soils. This paper describes the first steps in demonstrating nanoclay (montmorillonite) additive as a sustainable alternative to traditional soil additives for erosion-control applications. In this regard, the erodibility characteristics of standard Proctor (SP) compacted, very silty sand amended with $0 \cdot 5-6 \%$ dry weight montmorillonite K10 (MK10) material was investigated at bench scale using the hole-erosion test (HET) apparatus. Parallel testing was performed on the same soil amended with $\mathbf{0 . 2 5 - 3 \%}$ cement for comparison. Substantial erosion resistance improvements were achieved for as little as 0.5-1\% MK10 content, comparable to cement addition, with the HET classification increasing from HET groups 1-2 for the highly erodible, compacted, very silty sand investigated to HET group 4 (moderately slow erosion) for the 1\% MK10-soil mixture. Further investigations indicated the erosion resistance classification of the improved soil was not altered for under-compaction that achieved only $80 \%$ SP maximum dry density or for compaction at \pm 2 percentage points from the identified SP optimum water content.

\section{Notation}

$C_{\mathrm{e}} \quad$ coefficient of erosion

$C_{\mathrm{U}} \quad$ coefficient of uniformity

$C_{\mathrm{Z}} \quad$ coefficient of curvature

$D_{\mathrm{t}} \quad$ hole diameter at time $t$

$g \quad$ gravitational constant

$I_{\mathrm{HET}} \quad$ erosion rate index

$i \quad$ hydraulic gradient

$i_{\mathrm{t}} \quad$ hydraulic gradient at time $t$

$\dot{m}_{t} \quad$ rate of soil mass removal per unit wall surface area of predrilled hole at time $t$

$N \quad$ loss on ignition

$R_{\mathrm{e}} \quad$ Reynolds number

$t \quad$ time

w water content

$w_{\text {opt }} \quad$ optimum water content for compaction

$\rho_{\mathrm{d}} \quad$ dry density

$\rho_{\mathrm{d} \max } \quad$ maximum dry density

$\rho_{\mathrm{w}} \quad$ density of water

$\sigma \quad$ standard deviation

$\tau_{\mathrm{c}} \quad$ critical shear stress for soil detachment

$\tau_{\mathrm{t}} \quad$ hydraulic shear stress at time $t$

\section{Introduction}

After overtopping, the next most common causes of failure for hydraulic earth structures (e.g. dykes, levees and dams) are internal erosion and piping induced by seepage flow, accounting for $46 \%$ of the 11192 case-study embankment dam failures investigated by Foster et al. (2000). Consequently, reducing susceptibility to internal erosion is an important issue in dam design and safety. Internal erosion is a progressive process involving the separation of the soil particles by hydrodynamic stresses and their transportation by seepage flow within the hydraulic earth structure and its soil foundation or from the earth structure into the soil foundation. The erosion rate is dependent on various factors, including fines content (particularly the proportion of clay particles), the soil's plasticity and dispersivity, moulding water content, dry density and degree of saturation, applied hydraulic gradient, clay mineralogy and possibly also the presence of cementing materials, such as iron oxides (Wan and Fell, 2004a). Preferential flow paths can develop within compacted earth-fill and (or) foundation materials on account of defects arising from hydraulic fracturing, cracking, plant roots and so on, with the resulting water flow detaching soil particles, leading to the formation and evolution of a continuous 'pipe' (piping) between the upstream and downstream sides. Laboratory investigations, such as those performed using the hole-erosion test (HET) (after Wan and Fell, 2002, 2004a, 2004b), provide insights of the internal erosion (piping) characteristics of soil testspecimens in terms of quantifying their critical hydraulic shear stress $\left(\tau_{\mathrm{c}}\right)$, coefficient of erosion $\left(C_{\mathrm{e}}\right)$ and erosion rate index $\left(I_{\mathrm{HET}}\right)$ parameter values. The HET method simulates smallscale progressive internal erosion in the test specimen by causing erosive enlargement of a horizontal predrilled hole on account of internal flow through the hole under a controlled 
head differential. The US Bureau of Reclamation (US BoR and ACE, 2015) has adopted this method as one approach of investigating concentrated leak erosion through small holes and confined cracks, akin to that probably occurring during the initiation of internal erosion and piping failures for hydraulic earth structures. As such, the HET method provides an established approach for assessing and categorising relative improvements in hydraulic erosion resistance characteristics.

Various methods are employed to improve the geotechnical properties of troublesome soils in order to mitigate against internal erosion and hence reduce the risk of piping failure occurring for hydraulic earth structures. These include soil improvement technologies (mass mixing) utilising traditional cement, lime (Garzón et al., 2015, 2016), fly ash, as well as silicate and adhesive substances, although these additives are invariably not environmentally friendly (Indraratna et al., 2013; Zomorodian and Koohpeyma, 2015). Significant successes have been achieved in identifying alternative soil additives compatible with the environment, including, for instance, biocementation by way of the microbial-induced calcite precipitation (MICP) process (Amin et al., 2017; Shahrokhi-Shahraki et al., 2015; Zomorodian et al., 2019a), as well as employing various biopolymers as grouting materials (Khatami and O'Kelly, 2013, 2018), with their potential applications in dam construction and operation activities reviewed in the paper by Aminpour and O'Kelly (2015).

With the fast expansion of nanotechnology and increasing restrictions on the use of traditional additives for soil improvement in geotechnical engineering practice, recent research efforts investigating methods that employ nanomaterials for soil improvement have demonstrated promising results (e.g. see Zomorodian et al., 2017, 2019b). Nanomaterials, defined as physical substances with at least one characteristic dimension ranging between 1 and $150 \mathrm{~nm}$, are the building blocks of practical nanotechnology and they can be physically and chemically manipulated for specific applications (Merck, 2019). Nanoclays (NCs) are nanoparticles of layered mineral silicates. Depending on their chemical composition and nanoparticle morphology, NCs are organised into several classes, such as montmorillonite and bentonite (both smectites), kaolinite, hectorite and halloysite, of which plate-shaped naturally occurring montmorillonite and bentonite are commonly used in materials applications. Montmorillonite consists of approximately 1-nm-thick aluminosilicate layers, surfacesubstituted with metal cations, and stacked in $\sim 10 \mu \mathrm{m}$ sized multilayer stacks (Merck, 2019).

Owing to specially enhanced surface properties arising from their particle shape, electrical charge and extremely large specific surface area (SSA), the NC additives generally interact vigorously with fine-grained soil particles (Zomorodian et al., 2019b). At micro-scale, the increase in SSA has a significant effect on the water-retention characteristics and chemical interactions between the soil particles and pore water. Even when present as a small proportion, the $\mathrm{NC}$ additive can significantly affect the soil physicochemical, hydraulic and engineering properties (Zhang, 2007). The NC particles fill the nanopore voids of the soil matrix, causing a reduction in pore-void volume, and reduce the distances between neighbouring soil particles on account of greater flocculation arising from enhanced inter-particle attraction forces.

To date, most of the research efforts in this field have focused on the effectiveness of various NC additives for soil improvement applications, quantifying the increase in hydraulic resistance and (or) improvements in geotechnical engineering properties achieved for various soils and mixing proportions investigated. Examples include the improvement in unconfined compressive strength (Arabani et al., 2012; Majeed and Taha, 2012; Neethu and Remya, 2013; Zomorodian et al., 2017) and reduction in permeability coefficient (Kananizadeh et al., 2011; Neethu and Remya, 2013) values achieved for particular test soils. In contrast, research work examining the use of nanomaterials for soil erosion-control applications has been limited. Notable studies include investigations of the effectiveness of NC additive (montmorillonite) for soil erosion control using wind tunnel experiments (Padidar et al., 2014) and stabilisation of natural loess soils using both laboratory pinhole-dispersivity testing and a pilot field study performed at one of the main irrigation channels of Gonbad Dam, northeastern Iran (Tabarsa et al., 2018).

This paper presents HET investigations on the use of commercial montmorillonite K10 (i.e. MK10) additive for achieving improvements in the hydraulic erosion resistance of standard Proctor (SP) compacted, very silty sand material. The erosion properties of various soil-MK10 mixtures are compared with those of the unamended highly erodible soil (control) and the same soil treated with traditional cement additive. The experimental work programme was comprised of three stages. First, SP-compacted test specimens were prepared from 0.5 to $6 \%$ MK10-soil mixtures (dry weight basis) and investigated using the HET apparatus to determine the repeatability of the testing procedure and the general improvement in erosion resistance achievable for this soil type. Next, the effect of various determining factors on the soil erodibility characteristics, including the moulding water content $(w)$, compaction energy, curing period and applied hydraulic gradient were investigated for the $1 \%$ MK10-soil mixture. In particular, the significance of a \pm 2 percentage points difference in the identified SP optimum water content $\left(w_{\text {opt }}\right)$ (typically allowable for field compaction operations) and a plausible $\pm 20 \%$ difference in the SP maximum dry density $\left(\rho_{\mathrm{d}} \max \right)$ value achieved were investigated. Finally, as this is a new admixture, it is critical to 
compare the performance with traditional admixtures. Hence, additional HETs were performed on identically prepared test specimens of the same soil amended with $0 \cdot 25-3 \%$ cement.

\section{Experimental}

\subsection{Materials}

For the purpose of this experimental investigation, quartz sand was mixed with fine-grained soil to produce a highly erodible composite test soil material comprising 45\% medium sand, $29 \%$ fine sand and $26 \%$ fines (see gradation curve presented in Figure 1).

The test soil had coefficients of uniformity $\left(C_{\mathrm{U}}\right)$ and curvature $\left(C_{\mathrm{Z}}\right)$ values of 14 and $3 \cdot 8$, respectively, with $<2.8 \%$ of the solid particles smaller than $5 \mu \mathrm{m}$ size. The Casagrande liquid limit and thread-rolling plastic limit values were measured as $20 \cdot 8$ and $20 \cdot 1 \%$, respectively, giving a plasticity index value of $0.7 \%$ - that is, the fraction passing the $425 \mu \mathrm{m}$ sieve was essentially non-plastic. Based on the gradation curve and consistency limit values, the test soil is classified as very silty sand according to BS 5930 (BSI, 2015). Based on Sherard's erosion resistance classification system (Sherard, 1953), the compacted well-graded cohesionless soil material is categorised as having intermediate piping resistance (category 2).

The montmorillonite material investigated, with a product name of Montmorillonite K (10) (Sigma-Aldrich, Saint Louis, Missouri, USA), was produced by calcination of montmorillonite in acidic condition. Tables 1 and 2 report some physical and chemical properties of MK10, which is not a hazardous substance according to regulation (EC) number 1272/2008

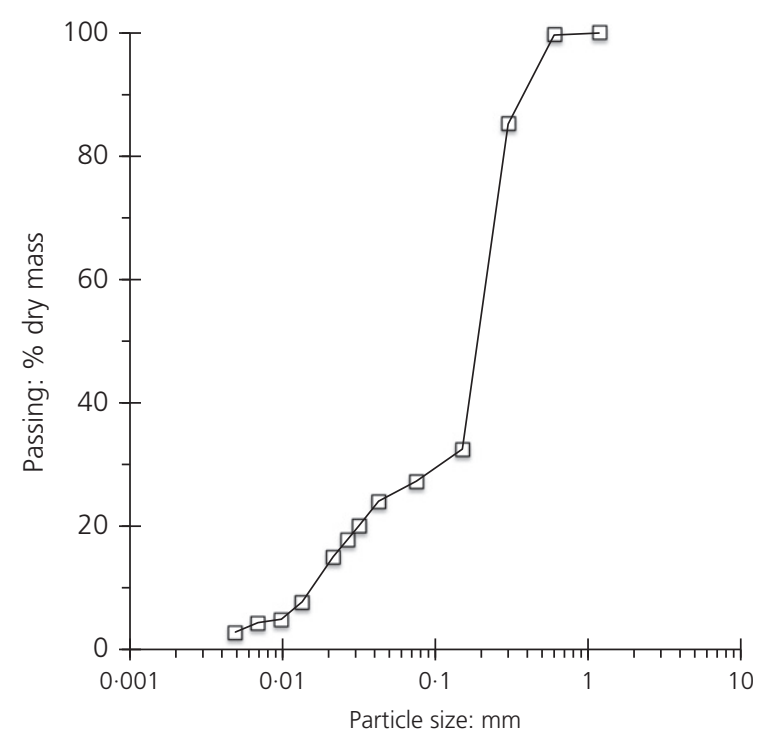

Figure 1. Grading curve for the very silty sand investigated
Table 1. Physical properties of MK10 montmorillonite (as reported by the manufacturer)

\begin{tabular}{ll} 
Property & Value \\
\hline Form & Powder \\
Colour & Off white \\
Odour & Odourless \\
Density: $\mathrm{Mg} / \mathrm{m}^{3}$ & $3 \cdot 0-3 \cdot 7$ \\
Size: $\mathrm{nm}$ & $1-2$ \\
$\mathrm{SSA}: \mathrm{m}^{2} / \mathrm{g}$ & $220-270$ \\
$\mathrm{pH}$ & $3-4$
\end{tabular}

Table 2. Chemical analysis of MK10 montmorillonite (as reported by the manufacturer)

\begin{tabular}{|cc|}
\hline Component & Fraction: \% \\
\hline Silicon dioxide & 50.95 \\
Aluminium oxide & 19.60 \\
Ferric oxide & 5.62 \\
Magnesium oxide & 3.29 \\
Calcium oxide & 1.97 \\
Sodium oxide & 0.98 \\
Potassium oxide & 0.86 \\
Titanium dioxide & 0.62 \\
$N$ & 16.11
\end{tabular}

Note: $N$, loss on ignition

(EC, 2019). MK10 does not refer to a specific reference mineral and its properties do not reflect that of most natural montmorillonite clays. Of particular note are MK10's particle size range of 1-2 nm and extremely large Brunner-EmmettTeller (BET) SSA value of $220-270 \mathrm{~m}^{2} / \mathrm{g}$. Compared to kaolinite or illite clays (SSA values of $10-20$ and $65-100 \mathrm{~m}^{2} / \mathrm{g}$, respectively (Day, 2001)), the use of MK10 powder is judged superior from the viewpoint that with significantly greater SSA, it interacts more vigorously with fine-grained soil particles for soil improvement applications. MK10 was investigated previously by Tabarsa et al. (2018) for stabilisation of natural loess soils (classified as low plasticity clay and silt) at one of the main irrigation channels of Gonbad Dam, north-eastern Iran.

\subsection{Methods}

\subsubsection{Test specimen preparation}

After oven drying at $105-110^{\circ} \mathrm{C}$ for a $24 \mathrm{~h}$ period, the test soil was allowed to cool to ambient laboratory temperature, disaggregated and then riffled to obtain identical sub-samples. NC suspensions with the desired concentrations were prepared by adding the required amounts of dry MK10 material to water at ambient laboratory temperature and then agitated using a high shear mixer to ensure compete homogenisation. This operation was performed using standard precautions (protective gloves and dust mask). 
The required amounts of the MK10 suspensions were added to the identical dry soil sub-samples to achieve targeted water content values and then thoroughly mixed using a low-speed mechanical mixer to produce homogeneous test materials with $0 \cdot 5-6 \%$ MK 10 contents. The moist sub-samples produced were individually stored for a $24 \mathrm{~h}$ period inside sealed plastic bags to achieve pore-water equalisation and allow better links to form between the MK10 and soil particles.

SP-compacted HET specimens were prepared for the various soil-MK10 mixtures. These specimens were formed by compaction in standard 1-1 moulds at the $w_{\text {opt }}$ value determined for the unamended test soil in accordance with BS 1377-4 (BSI, 1990). SP-compaction testing was also performed for the soil with $0 \cdot 5,1$ and $1 \cdot 5 \%$ MK10 contents to investigate the extent that the additive may alter the SP $w_{\text {opt }}$ and $\rho_{\mathrm{d} \text { max }}$ values compared to those obtained for the unamended soil. All compacted specimens were allowed to stand undisturbed and at constant water content for periods of 1, 7, 14 and $28 \mathrm{~d}$ before performing the HETs.

In examining the effect of compaction energy level (dry density), additional HET specimens were prepared at 80 and $120 \%$ of the identified SP $\rho_{\mathrm{d} \text { max }}$ value for the unamended soil. For sample preparation at 80 and $120 \% \rho_{\mathrm{d}} \max$, the same number of rammer blows was used in forming each of the three layers comprising the test specimen, but the blow count was reduced or increased accordingly to achieve the targeted specimen dry density value.

For all test specimens, the final (third) compacted layer of the test specimen was trimmed flush with the top rim of the compaction mould and the specimen mass, water content and dry density were determined in the usual manner. After removing the base plate from the compaction mould, a $6 \mathrm{~mm}$-diameter hole was formed along the specimen axis using a drill press and wood auger bit, which was advanced slowly during the drilling process. Both ends of the compacted specimen were then wrapped in plastic film (to prevent any moisture loss) and allowed to cure for periods of between 1 and $28 \mathrm{~d}$ before performing the HET investigations.

\subsubsection{Hole-erosion testing}

Since no hole-erosion testing standard currently exists, the testing and analysis methods adopted in this investigation are those employed in the original HET procedures described by Wahl et al. (2008) and Wan and Fell (2004a).

The test-specimen contained within the 1-1 compaction mould was assembled in the permeameter-cell component (Figure 2(a)) of the HET apparatus set-up (Figure 2(b)). All specimens were tested with their final compacted layer positioned on the upstream side, with the predrilled $6 \mathrm{~mm}$-diameter erosion hole horizontally aligned.

The hydraulic lines were slowly filled with water and any air present was bled from the piezometer tubes. The upstream and downstream water-supply tanks were positioned to produce the required starting head differential value. Water was then allowed to circulate through the predrilled hole along the testspecimen axis, with measurement of the flow rate. Since the HETs commenced by applying sufficiently low differential head, the generated hydraulic shear stress for each compacted specimen was less than the critical value, such that little or no erosion initially occurred. Over time, the system usually entered a progressive erosion phase - that is, enlargement of the hole diameter occurred, thereby increasing the flow rate causing an accelerating erosion rate. If the flow rate stabilised for the set hydraulic head differential, then the upstream water-supply tank was raised in steps until progressive erosion was initiated. On achieving the progressive erosion condition, the head differential was maintained constant and the test continued for a long enough period to measure a definite acceleration of the flow (erosion) rate. After completion of each test, the water contained in the upstream and downstream flowchambers of the HET permeameter cell was allowed to drain, the cell carefully dismantled and the final diameter and effective length of the constricted portion of the eroded hole determined from Vernier calliper measurements.

\subsection{Experimental HET programme}

The soil mixtures investigated had $0 \cdot 5,1,1 \cdot 5,2,3,4,5$ and $6 \%$ dry-weight MK10 contents. For the 0.5, 1 and 1.5\% MK10 contents, specimens were prepared in triplicate and HET tested to demonstrate that the results are experimentally repeatable. In total, 41 HETs were performed on the various soil-MK10 mixtures and one HET on the unamended soil (control) for the same applied hydraulic gradient $(i)$ value of $7 \cdot 2$, which was calculated as the ratio of the constant head differential to the length of the eroding hole.

To investigate the effects of moulding water content and compaction energy level (dry density), four additional HET specimens were prepared by SP compaction of the $1 \%$ MK10-soil mixture at $w_{\text {opt }} \pm 2 \%$ and for 80 and $120 \%$ of the SP $\rho_{\mathrm{d} \text { max }}$ value identified for the unamended soil. Again, a hydraulic gradient value of $7 \cdot 2$ was employed for these HETs.

To investigate the effect of hydraulic gradient on the erodibility, six additional HETs investigating $i=0 \cdot 43-10 \cdot 3$ were performed on SP-compacted specimens of the $1 \%$ MK10-soil mixture prepared at the $w_{\text {opt }}$ value identified for the unamended soil. This hydraulic gradient range was defined by a head differential of between $50 \mathrm{~mm}$ and the maximum value of $1180 \mathrm{~mm}$ that could be applied using the experimental 


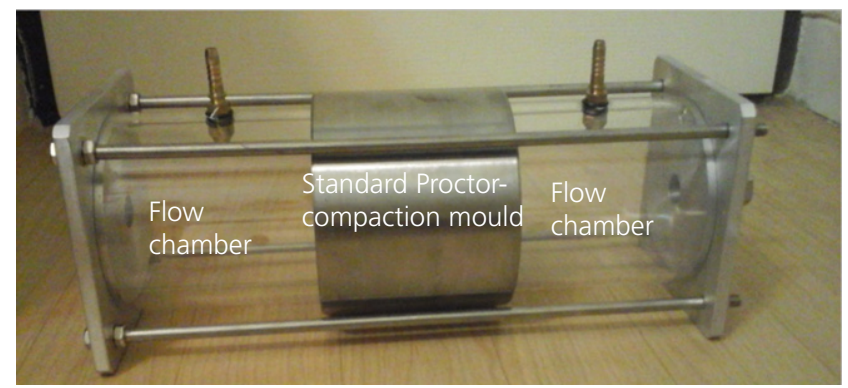

(a)

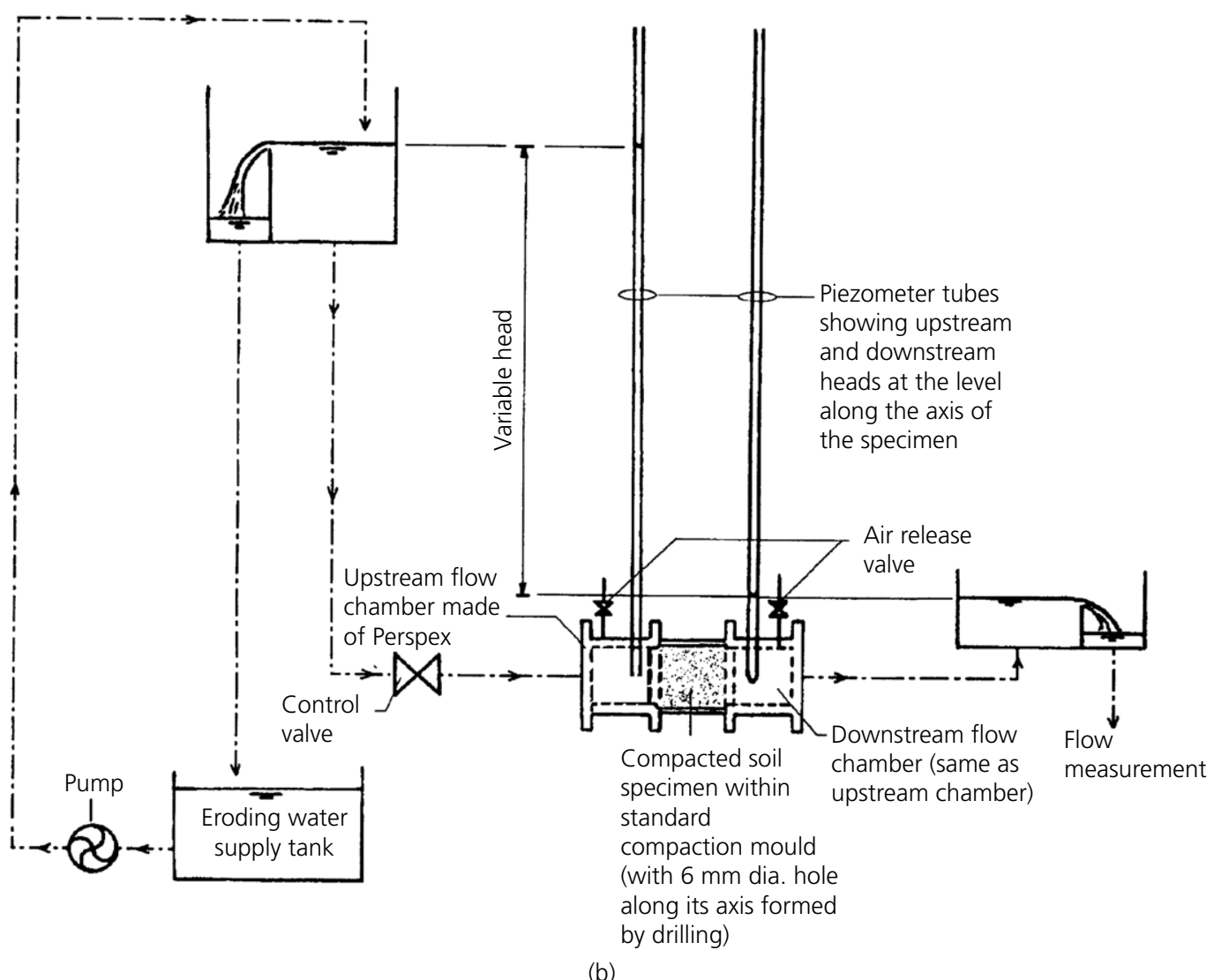

Figure 2. HET testing: (a) permeameter cell assembly employed in this investigation; (b) schematic diagram of experimental set-up (source: adapted from Wan and Fell (2004a))

set-up employed. HETs investigating this range of hydraulic gradient values were also performed on SP-compacted unamended soil specimens. A similar hydraulic gradient range was investigated for the HET testing programme described in Wan and Fell (2004a).

Additional HETs were performed in triplicate on test specimens prepared by SP compaction of the same test soil mixed with $0 \cdot 25,0 \cdot 5,1,2$ and $3 \%$ cement additive at the SP $w_{\text {opt }}$ value identified for the unamended soil, investigating curing periods of $1,7,14$ and $28 \mathrm{~d}$. In total, 60 HETs were performed on these soil-cement mixtures for a hydraulic gradient value of $7 \cdot 2$.

\section{HET data analysis using the Wan and Fell approach}

Before presenting the experimental results and analysis for the 0.5-6\% MK10-soil and 0.25-3\% cement-soil mixtures along with the unamended soil, this section gives an overview of some key elements of the Wan and Fell HET analysis approach and their soil erodibility classification system. 
Depending on the prevailing HET conditions, the laminar or turbulent flow state $\left(R_{\mathrm{e}}<2000\right.$ and $>2000$, respectively (Wahl et al., 2008); where $R_{\mathrm{e}}$ is the Reynold's number) can apply. At time period $t$ during the turbulent state (i.e. progressive erosion phase), the relationship between the erosion rate $\left(\dot{m}_{t}\right)$ and the hydraulic shear stress $\left(\tau_{\mathrm{t}}\right)$ acting along the wall surface of the erosion hole is expressed by the detachment-driven erosion equation, as follows

1. $\dot{m}_{t}=C_{\mathrm{e}}\left(\tau_{\mathrm{t}}-\tau_{\mathrm{c}}\right)$

where $\dot{m}_{t}$ is the rate of soil mass removal per unit wall surface area of the erosion hole at time $t\left(\mathrm{~kg} /\left(\mathrm{s} / \mathrm{m}^{2}\right)\right), C_{\mathrm{e}}$ is the coefficient of erosion $(\mathrm{s} / \mathrm{m})$, which can range over several orders of magnitude for soils of engineering interest, and $\tau_{\mathrm{c}}$ is the critical (threshold) hydraulic shear stress required for soil particle detachment $(\mathrm{Pa})$.

The internal erosion characteristics are described by the erosion rate index $\left(I_{\mathrm{HET}}\right.$ : Equation 2$)$, which quantifies the increase in erosion rate with respect to an increase in hydraulic shear stress during the progressive erosion phase.

2. $I_{\mathrm{HET}}=-\log _{10} C_{\mathrm{e}}$

Typically, the value of $I_{\mathrm{HET}}$ can range from unity to just above 6 , with larger values indicating greater erosion resistance (i.e. lower erosion rate). The $I_{\mathrm{HET}}$ result is usually reported as an integer, corresponding to a group number, each having an associated descriptive term used in categorising the erosion characteristics (after Wan and Fell, 2004a). For this investigation, the $I_{\mathrm{HET}}$ results are reported to one decimal place in order to more accurately quantify relative changes in erosion resistance characteristics arising from the small percentage MK10 additions.

\section{Results and discussion}

\subsection{Compaction properties}

SP compaction of the unamended silty sand produced a $\rho_{\mathrm{d} \max }$ value of $1.77 \mathrm{t} / \mathrm{m}^{3}$ at its $w_{\text {opt }}$ value of $12.8 \%$ (Figure 3 ). It was found that MK10 and cement additions for their small content ranges investigated produced negligible changes in these $w_{\mathrm{opt}}$ and $\rho_{\mathrm{d} \text { max }}$ values, in agreement with the findings deduced by Tabarsa et al. (2018) from synthesis of compaction data for various fine-grained soil-MK10 mixtures investigated in the papers by Majeed et al. (2014), Taha and Taha (2012) and Zhang et al. (2004). This justifies compaction of the soilMK10 and soil-cement mixtures at the SP $w_{\text {opt }}$ value identified for the unamended soil - that is, SP compaction at the same moulding water content of $12.8 \%$ produced essentially similar dry density values for all HET test specimens.

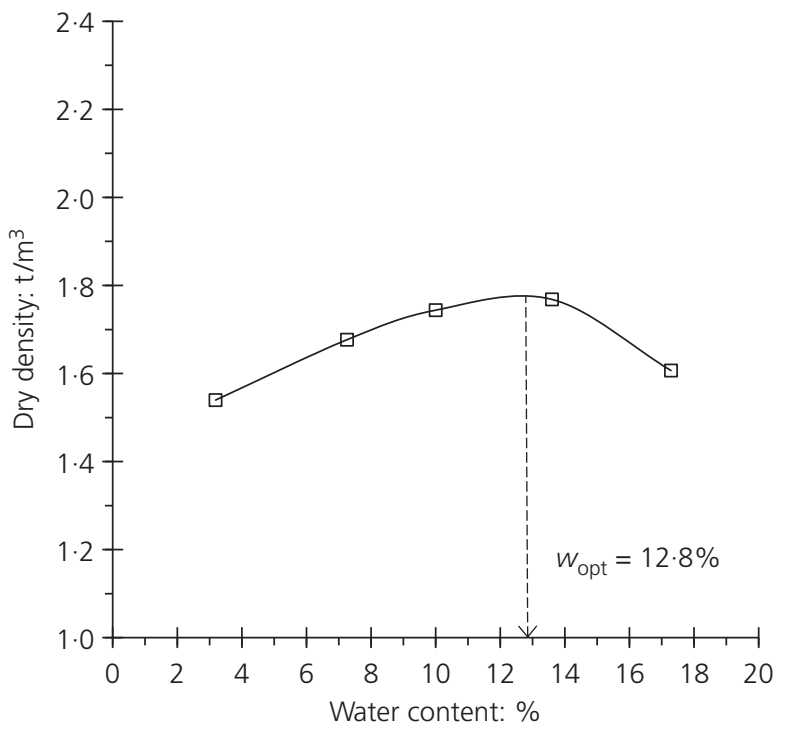

Figure 3. SP-compaction curve for unamended test soil

\subsection{HET properties}

As described in the papers by Wan and Fell (2004a) and Wahl et al. (2008); from measurements of the hydraulic gradient and accelerating flow (erosion) rate through the predrilled hole during the progressive erosion phase, the values of pertinent parameters are computed as follows (refer to the series of plots for the 1\% MK10-soil specimen presented in Figure 4). From experimental observations, apart from the unamended soil specimen, localised scouring did not occur at the upstream or downstream ends of the erosion hole - that is, no significant shortening of the length of the predrilled hole occurred over the duration of the HETs.

The friction factor values for the laminar and turbulent flow conditions occurring at the start and end, respectively, of each HET were computed from the measured initial and final holediameter and flow rate values, with the onset of turbulence assumed to occur for $R_{\mathrm{e}} \geq 2000$ (Wahl et al., 2008). With the applied head differential known and the flow rate measured over the course of each HET (Figure 4(a)), values of the eroding hole diameter $\left(D_{\mathrm{t}}\right)$ were computed for each time step (Figure 4(b)), assuming a linear variation of the friction factor values with elapsed time. The calculated final hole diameter was cross-checked with the specimen hole diameter measured at the end of the HET (after carefully dismantling the permeameter cell). A polynomial function relating the computed $D_{\mathrm{t}}$ value to $t$ was determined, with its time derivative defining the erosion rate (first $y$-axis in Figure 4(c)). As the initial applied head differential was insufficient to cause immediate progressive erosion, but with progressive erosion usually ensuing over time for no head increase, the evolution of the hole diameter 


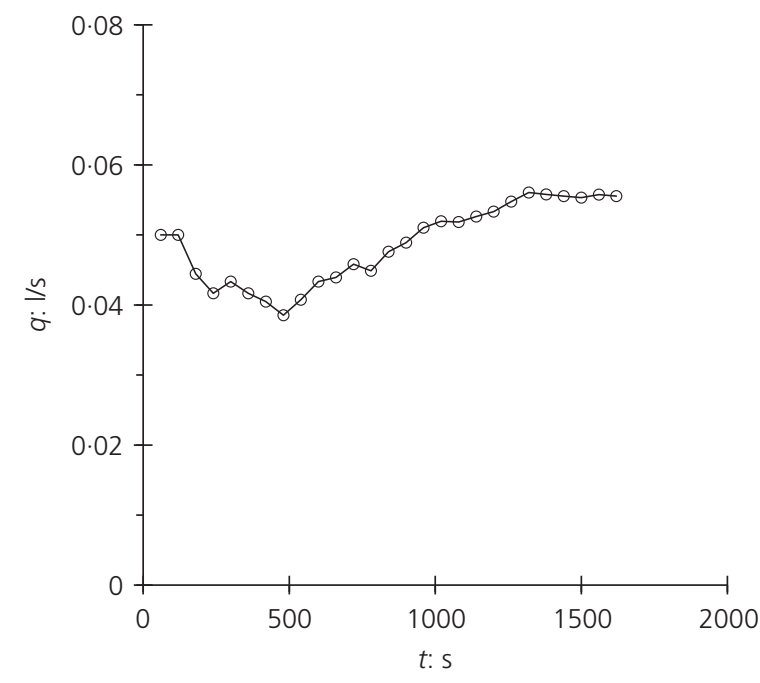

(a)

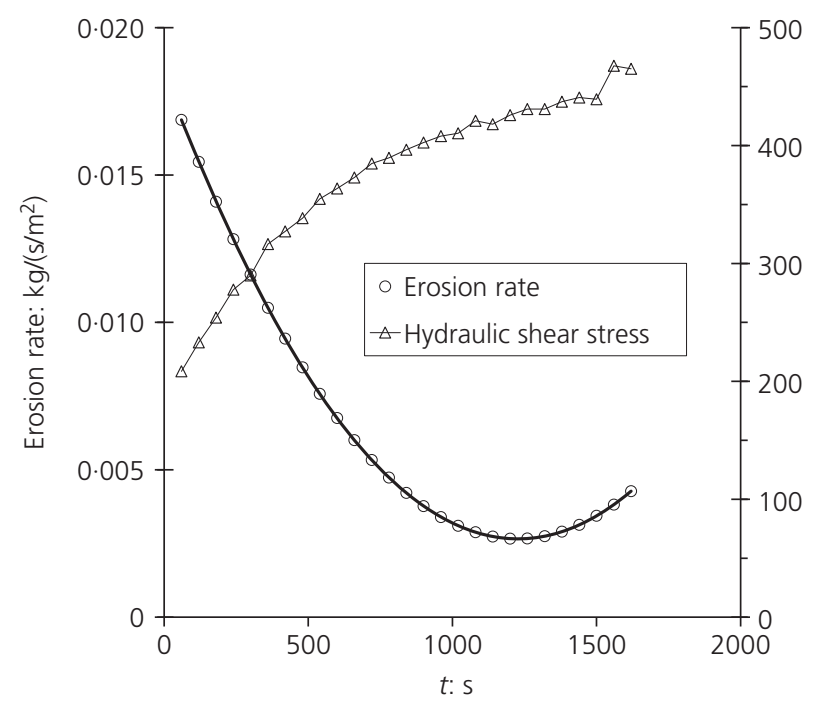

(c)

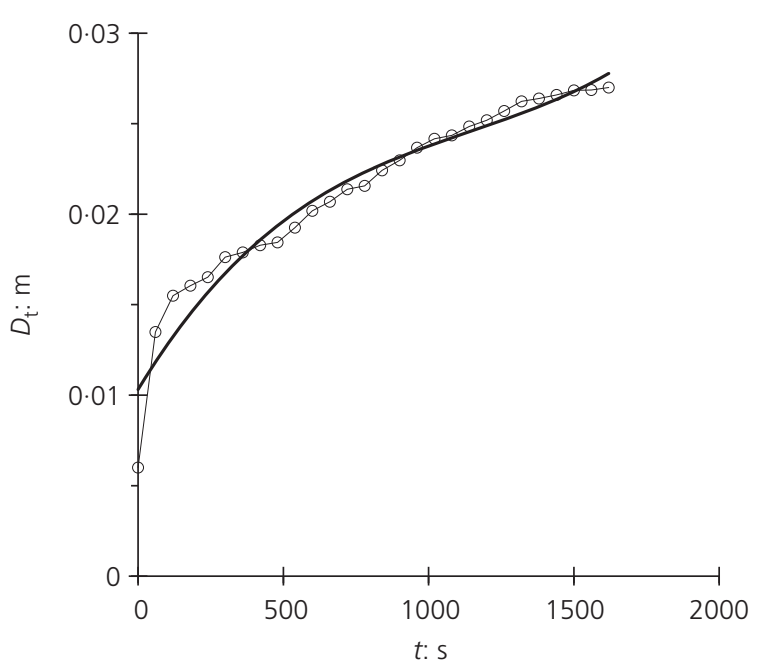

(b)

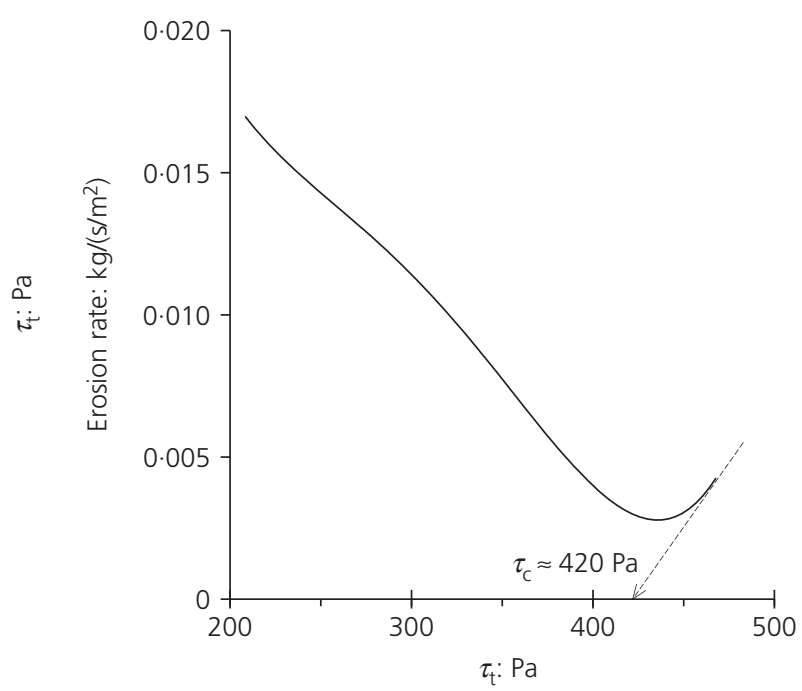

(d)

Figure 4. HET results for SP-compacted 1\% MK10-soil mixture: (a) measured flow rate against time for constant head differential; (b) computed hole diameter against time, fitted with third-order polynomial for modelling the hole diameter evolution; (c) computed erosion rate and hydraulic shear stress against time; (d) erosion rate against hydraulic shear stress

was modelled using a third-order polynomial function. Hence, this approach produced a second-order-polynomial erosion rate against time relationship (as evident for the $1 \%$ MK10 soil results presented in Figure 4(c)), with the erosion rate $\dot{m}_{t}$ value $\left(\mathrm{kg} /\left(\mathrm{s} / \mathrm{m}^{2}\right)\right)$ computed as
3. $\dot{m}_{t}=\frac{\rho_{\mathrm{d}}}{2} \frac{\mathrm{d} D_{\mathrm{t}}}{\mathrm{d} t}$

where $\rho_{\mathrm{d}}$ is the dry density of the test specimen $\left(\mathrm{kg} / \mathrm{m}^{3}\right)$.
For the short time intervals considered, the flow rate is assumed at steady state and the increasing hydraulic shear stress, $\tau_{\mathrm{t}}(\mathrm{Pa})$, acting along the wall surface of the eroding hole at time $t$ is calculated as follows

4. $\tau_{t}=\rho_{\mathrm{w}} g i_{\mathrm{t}} \frac{D_{\mathrm{t}}}{4}$

where $\rho_{\mathrm{w}}$ is the density of water $\left(\mathrm{kg} / \mathrm{m}^{3}\right), g$ is the gravitational constant $\left(9.81 \mathrm{~m} / \mathrm{s}^{2}\right)$ and $D_{\mathrm{t}}$ and $i_{\mathrm{t}}$ are the diameter of the 
eroding hole $(\mathrm{m})$ and hydraulic gradient acting across its effective length $(\mathrm{m})$, respectively, at time $t(\mathrm{~s})$.

As mentioned earlier, apart from the unamended soil specimen, the hole erosion tended to be reasonably uniform over the duration of the HETs (e.g. see Figure 5), with no significant shortening of the predrilled-hole length. For the purpose of performing the various calculations described above, the mean of the measured upstream and downstream hole diameters was for cross-checking the calculated final hole diameter.

The computed erosion rate values are plotted against the hydraulic shear stress, with the values of $C_{\mathrm{e}}$ and $\tau_{\mathrm{c}}$ determined as the gradient and $x$-intercept of the best-fit line through the experimental data points for the progressive erosion period (e.g. see the case for the 1\% MK10-soil specimen presented in Figure 4(d)). Since the generated hydraulic shear stress was initially less than its critical value (i.e. $\tau_{\mathrm{t}}<\tau_{\mathrm{c}}$ ), little or no erosion of the central predrilled hole along the compacted specimen initially occurred for the various soil mixtures. In fact, despite the hydraulic shear stress increasing in value during the early phase of the HETs, the computed erosion rate exhibited the characteristic reduction in value with elapsed time (e.g. see Figures 4(c) and 4(d) for $\tau_{\mathrm{t}}<420 \mathrm{~Pa}$ ). For the progressive erosion phase (i.e. $\tau_{t}>\tau_{\mathrm{c}}$ ), however, the flow rate for the constant applied head differential steadily increased producing the characteristic V-shaped experimental data trace of erosion rate against hydraulic shear stress, as evident from Figure 4(d).

\subsubsection{Repeatability of HETs}

As a demonstration of the HET repeatability, Table 3 lists the $I_{\mathrm{HET}}$ results obtained for SP-compacted specimens

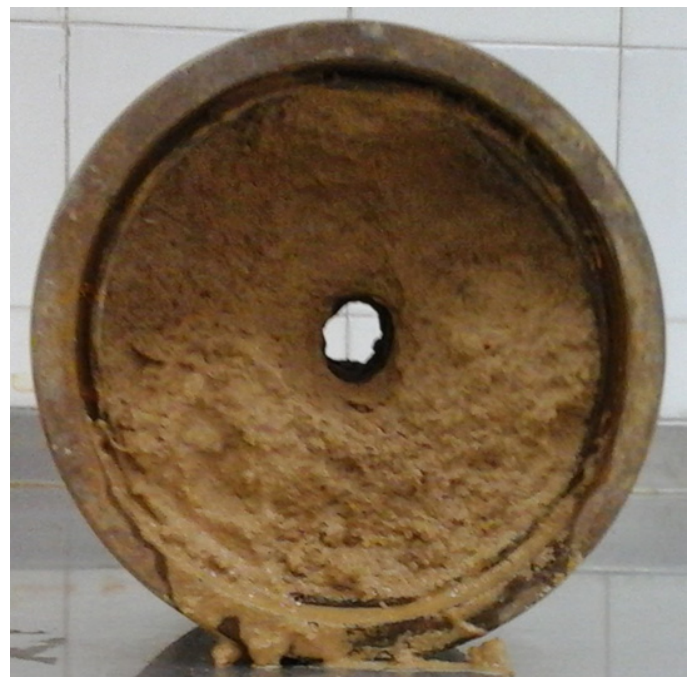

Figure 5. Uniformity of the eroded hole observed for SP-compacted 1\% MK10-soil specimen after test completion
Table 3. $I_{\text {HET }}$ results for SP-compacted soil-MK10 mixtures with $w=12 \cdot 8 \%$ and $i=7 \cdot 2$.

\begin{tabular}{|c|c|c|c|}
\hline \multirow{2}{*}{$\begin{array}{l}\text { Curing } \\
\text { period: } d\end{array}$} & \multicolumn{3}{|c|}{$I_{\text {HET }}$} \\
\hline & $0.5 \%$ MK 10 & $1.0 \%$ MK 10 & $1.5 \% \mathrm{MK} 10$ \\
\hline 1 & 3.9 & $4 \cdot 2$ & $4 \cdot 2$ \\
\hline 1 & 3.9 & $4 \cdot 2$ & $4 \cdot 2$ \\
\hline 1 & 3.9 & $4 \cdot 1$ & $4 \cdot 2$ \\
\hline 7 & 3.9 & $4 \cdot 2$ & $4 \cdot 2$ \\
\hline 7 & 3.9 & $4 \cdot 2$ & $4 \cdot 2$ \\
\hline 7 & 3.9 & $4 \cdot 2$ & $4 \cdot 2$ \\
\hline 14 & $4 \cdot 3$ & $4 \cdot 4$ & $4 \cdot 7$ \\
\hline 14 & $4 \cdot 3$ & 4.5 & $4 \cdot 6$ \\
\hline 14 & $4 \cdot 4$ & 4.6 & 4.6 \\
\hline 28 & $4 \cdot 4$ & $4 \cdot 7$ & $4 \cdot 7$ \\
\hline 28 & $4 \cdot 6$ & 4.7 & $4 \cdot 8$ \\
\hline 28 & 4.6 & $4 \cdot 8$ & $4 \cdot 8$ \\
\hline
\end{tabular}

prepared using the test soil with $0 \cdot 5,1$ and $1 \cdot 5 \%$ MK10 additions for $w=12 \cdot 8 \%$ and $i=7 \cdot 2$. As evident from this table, for a given MK10 content and curing period, the $I_{\mathrm{HET}}$ results obtained for the three replicates tested confirm that inherent variability was small, with the $I_{\mathrm{HET}}$ values consistently increasing marginally for increasing curing period.

\subsubsection{Effect of MK10 addition on erosion resistance}

Figure 6 presents the $I_{\mathrm{HET}}$ values computed for the one-daycured SP-compacted soil-MK10 mixtures tested for $i=7 \cdot 2$. Included in this figure are the six erodibility classification groupings after Wan and Fell (2002, 2004a, 2004b). Note that, as described later in the paper, complete erosion of SP-compacted unamended soil occurred within a few minutes of starting the HET for $i \geq 1 \cdot 13$, such that its experimental

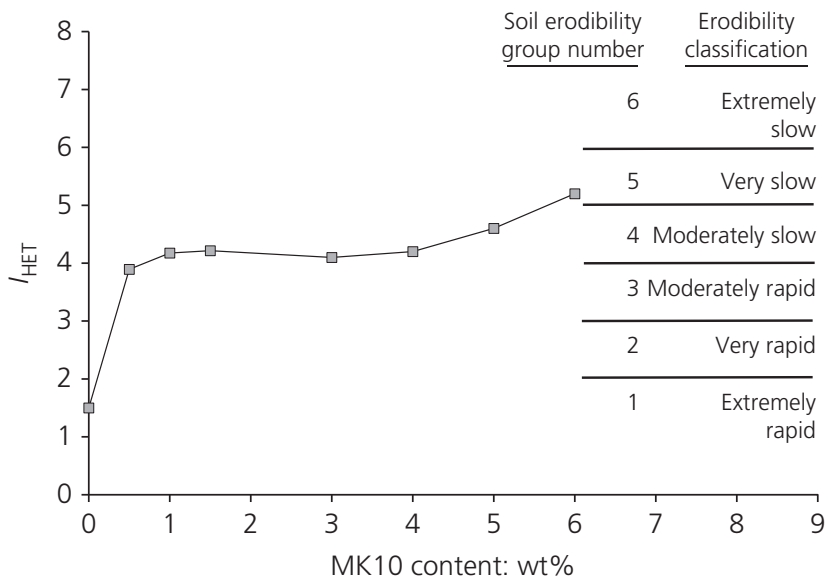

Figure 6. Effect of MK10 addition on HET erodibility of one-daycured SP-compacted very silty sand material at $12 \cdot 8 \%$ water content $(i=7 \cdot 2)$ 
values of $\tau_{\mathrm{c}}, C_{\mathrm{e}}$ and $I_{\mathrm{HET}}$ could not be determined for $i=7 \cdot 2$. In this instance (i.e. very/extremely rapid erosion), the compacted unamended soil specimen is categorised as HET group 1 or 2 material (i.e. $I_{\mathrm{HET}}=1$ or 2). Hence, for the purposes of evaluating the improvements in erosion resistance achieved for the various soil-MK10 mixtures, the unamended soil was assigned an $I_{\mathrm{HET}}$ value of $1 \cdot 5$.

Referring to Figure 6: compared to unamended soil, the $I_{\mathrm{HET}}$ values for the soil-MK10 mixtures were substantially greater, with a step increase in $I_{\mathrm{HET}}$ value achieved for as little as $0.5 \%$ MK10 addition. The difference in HET erosion resistance between 0.5 and $4 \%$ MK10 content was marginal, with $I_{\mathrm{HET}}$ values varying between 3.9 and 4.2 over this range. A tentative linear increase in the $I_{\mathrm{HET}}$ magnitude occurs for increasing MK10 content from $\sim 4 \%$ to the maximum value of $6 \%$ investigated. According to the erodibility classification groupings after Wan and Fell (2002, 2004a, 2004b), moderately rapid, moderately slow and very slow erosion occurs for MK10 additions of $0 \cdot 5,1-5$ and $6 \%$, respectively (i.e. HET groups 3 , 4 and 5 , respectively).

As explained in the papers by Huang and Wang (2016) and Zhang (2007), even when present as only a small proportion, the MK10 particles interact vigorously with the fine-grained soil particles on account of their tiny size (1-2 nm), electrical charge and extremely large SSA of $220-270 \mathrm{~m}^{2} / \mathrm{g}$. As described earlier, the huge increases in SSA for the soil mixtures with increasing MK10 content has a significant effect on the soil's water-retention characteristics and chemical interactions between the solid particles and moisture at the micro-scale. The resulting enhanced inter-particle attraction forces acting between the MK10 particles and fine-grained soil particles increase the soil's cohesion and shear resistance capacity (Bahari and Shahnazari, 2015). In other words, the improved

Table 4. $I_{\text {HET }}$ results for SP-compacted soil-cement (C) mixtures with $w=12 \cdot 8 \%$ and $i=7 \cdot 2$

\begin{tabular}{|c|c|c|c|c|c|}
\hline \multirow{2}{*}{$\begin{array}{l}\text { Curing } \\
\text { period: } \mathrm{d}\end{array}$} & \multicolumn{5}{|c|}{$I_{\text {HET }}$} \\
\hline & $0.25 \% \mathrm{C}$ & $0.5 \% \mathrm{C}$ & $1.0 \% \mathrm{C}$ & $2.0 \% \mathrm{C}$ & $3.0 \% \mathrm{C}$ \\
\hline 1 & $3 \cdot 8$ & 3.7 & 4.4 & $4 \cdot 5$ & 4.4 \\
\hline 1 & 3.8 & $4 \cdot 2$ & $4 \cdot 1$ & $4 \cdot 1$ & $4 \cdot 4$ \\
\hline 1 & 4.0 & 4.0 & $4 \cdot 3$ & $4 \cdot 3$ & $4 \cdot 3$ \\
\hline 7 & $4 \cdot 1$ & $4 \cdot 1$ & $4 \cdot 4$ & 4.5 & 4.6 \\
\hline 7 & $4 \cdot 2$ & $4 \cdot 2$ & 4.4 & 4.6 & 4.6 \\
\hline 7 & 4.0 & $4 \cdot 2$ & $4 \cdot 3$ & 4.6 & $4 \cdot 7$ \\
\hline 14 & $4 \cdot 1$ & $4 \cdot 4$ & $4 \cdot 6$ & $4 \cdot 7$ & $4 \cdot 7$ \\
\hline 14 & $4 \cdot 2$ & $4 \cdot 5$ & 4.4 & $4 \cdot 7$ & 4.8 \\
\hline 14 & $4 \cdot 3$ & 4.6 & $4 \cdot 7$ & $4 \cdot 7$ & $4 \cdot 8$ \\
\hline 28 & $4 \cdot 3$ & 4.5 & 4.8 & $4 \cdot 8$ & $5 \cdot 1$ \\
\hline 28 & $4 \cdot 3$ & 4.6 & 4.8 & 5.0 & 4.9 \\
\hline 28 & $4 \cdot 3$ & 4.6 & 4.9 & 5.0 & 4.9 \\
\hline
\end{tabular}

erosion resistance measured for the various soil-MK10 mixtures occurred on account of enhanced inter-particle attraction forces and significantly reduced pore-void volume, with the latter dramatically reducing their permeability coefficient values compared to the unamended soil.

\subsubsection{Effects of moulding water content and compaction energy level}

The HET results for SP-compacted 1\% MK10-soil specimens prepared at $w=10 \cdot 8,12 \cdot 8\left(w_{\text {opt }}\right)$ and $14 \cdot 8 \%$ are presented in Figure 7.

As evident from Figure 7, compared to $w_{\mathrm{opt}}$, the $I_{\mathrm{HET}}$ values for specimens SP compacted at water contents of $w_{\mathrm{opt}}-2 \%$ and $w_{\text {opt }}+2 \%$ were marginally lower and higher, respectively that is, other factors being equal, SP compaction at the upper end of the typically allowable field water content range for compaction of $w_{\mathrm{opt}} \pm 2 \%$ produced a marginally higher $I_{\mathrm{HET}}$ value, in agreement with the experimental findings reported in the papers by Benahmed and Bonelli (2012), Wan and Fell (2004a, 2004b) and Lim (2006). The slightly greater erodibility of the predrilled hole for the $1 \%$ MK10-soil specimen compacted on the dry side of the $w_{\text {opt }}$ value can be explained in terms of its compaction behaviour. Typical of compaction for dry of the optimum water content, soil agglomerations (clods) remained independent for compaction of the 1\% MK10-soil mixture at $w_{\text {opt }}-2 \%$ - that is, the compaction process did not produce sufficient remoulding of the clods, such that this test specimen was more heterogeneous.

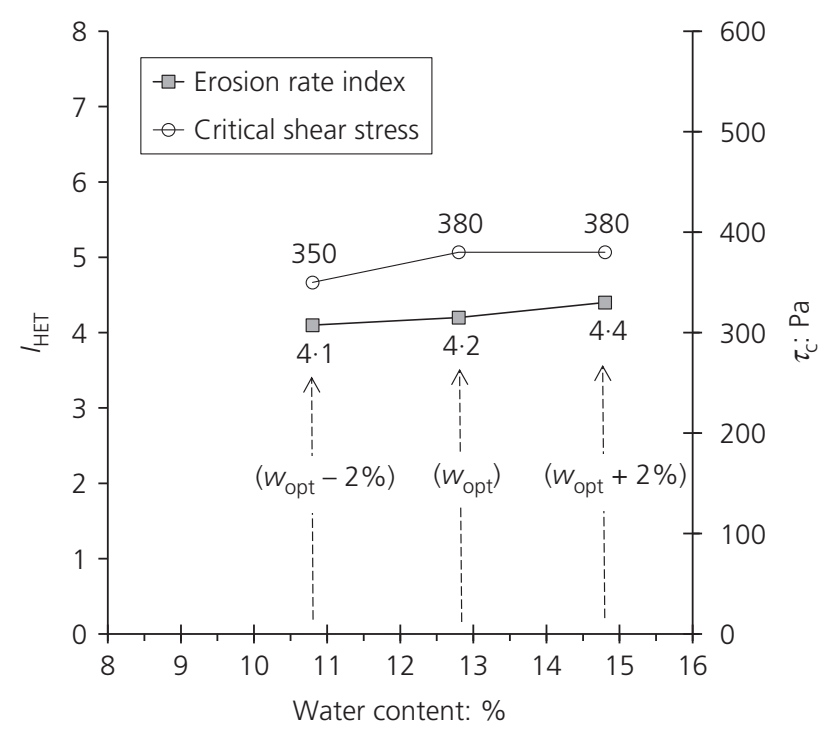

Figure 7. Effect of moulding water content on erosion rate index and critical shear stress for SP-compacted 1\% MK10-soil specimens $(i=7 \cdot 2)$ 
The HET results for the $1 \%$ MK10-soil mixture prepared at 80,100 and $120 \%$ of the SP $\rho_{\mathrm{d} \text { max }}$ value obtained for $12 \cdot 8 \%$ water content (i.e. at SP $w_{\text {opt }}$ ) are presented in Figure 8. As expected, greater erosion resistance (i.e. higher $I_{\mathrm{HET}}$ and $\tau_{\mathrm{c}}$ values) was achieved for the higher compaction level (dry density). This can be simply explained as follows. For a given soil, the $w_{\text {opt }}$ value decreases for higher compaction effort. As such, the specimen compacted at $12.8 \%$ water content to achieve $1.2 \times \mathrm{SP} \rho_{\mathrm{d} \max }$ was compacted at a water content greater than optimum (on wet side of optimum). In other words, compared to SP compaction at $12.8 \%$ water content, this test specimen would have had a lower air-void content, lower permeability-coefficient value and presumably higher shear resistance capacity. The corollary applies for the test specimen prepared by compaction at $12 \cdot 8 \%$ water content to achieve $0.8 \times \mathrm{SP} \rho_{\mathrm{d} \text { max }}$ (i.e. on dry side of the optimum) - that is, referring to Figure 8 , the critical shear stress $\left(\tau_{\mathrm{c}}\right)$ increased overall for greater compaction effort.

Significant findings are, therefore, that compared to $\mathrm{SP} \rho_{\mathrm{d} \text { max }}$, the improvement in erosion resistance achieved for $1 \%$ MK10 addition reduced only marginally (from $I_{\mathrm{HET}}$ of $4 \cdot 2$ to $4 \cdot 1$ ) for the lower dry density of $0.8 \times \mathrm{SP} \rho_{\mathrm{d} \max }$ (Figure 8) and for a moulding water content value at the lower end (i.e. $w_{\text {opt }}-2 \%$ ) of the typically allowable water content range for field compaction. Likewise, only marginal improvements in erosion resistance $\left(I_{\mathrm{HET}}\right.$ increasing from $4 \cdot 2$ to $\left.4 \cdot 4\right)$ were achieved for compaction at the higher end (i.e. $w_{\text {opt }}+2 \%$ ) of the allowable water content range or for the higher dry density of $1.2 \times \mathrm{SP}$ $\rho_{\mathrm{d} \text { max }}$. Overall, when the $I_{\mathrm{HET}}$ results for the $1 \% \mathrm{MK} 10$-soil

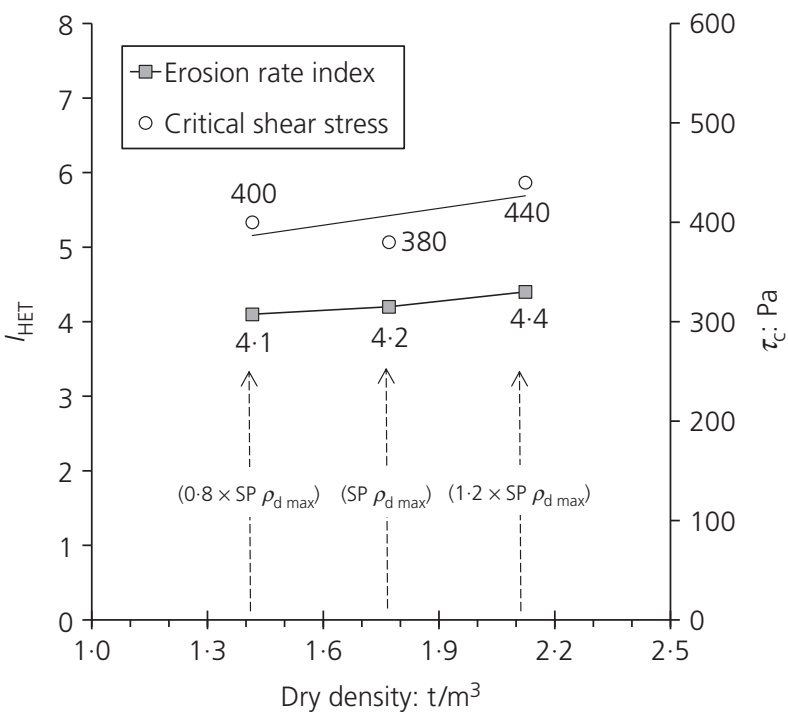

Figure 8. Effect of compaction level on erosion rate index and critical shear stress for $1 \%$ MK10-soil specimens compacted at $12 \cdot 8 \%$ water content $(i=7 \cdot 2)$ mixture are considered in their conventional integer format, there is no change in the experimental $I_{\mathrm{HET}}$ group number (moderately slow erosion) obtained for $w_{\text {opt }} \pm 2 \%$ or $0 \cdot 8-1 \cdot 2 \times \mathrm{SP} \rho_{\mathrm{d} \max }$.

\subsubsection{Effect of curing period}

From Table 3, longer curing periods before performing the HETs produce marginally higher $I_{\text {HET }}$ values, with a $13-16 \%$ increase in $I_{\mathrm{HET}}$ achieved by increasing the curing period from 1 to $28 \mathrm{~d}$ for the $0 \cdot 5-1 \cdot 5 \%$ MK10-soil mixtures SP-compacted at $w_{\text {opt }}$ and HET tested using $i=7 \cdot 2$.

\subsubsection{Effect of hydraulic gradient}

Figure 9 presents the HET results for the 1\% MK10-soil specimens SP compacted at $w_{\mathrm{opt}}=12 \cdot 8 \%$, investigating hydraulic gradients ranging $0 \cdot 43-10 \cdot 3$. From this figure, the value of $I_{\mathrm{HET}}$ for these specimens increased with increasing hydraulic gradient. However, the overall erosion resistance improvement achieved for $i=3 \cdot 3-10 \cdot 3$ was relatively independent of hydraulic gradient, with a mean $I_{\mathrm{HET}}$ value of $4 \cdot 1(\sigma=0 \cdot 18)$ over this range - that is, the moderately slow erosion classification for this soil-MK10 mixture was maintained despite the significant increase in applied hydraulic gradient. Included in Figure 9 is the experimental data point determined at the lowest $i$ value of 0.43 investigated for the unamended soil. As described earlier, unamended soil specimens eroded extremely rapidly for higher hydraulic gradients examined and, following the erodibility classification system after Wan and Fell (2002, 2004a, 2004b),

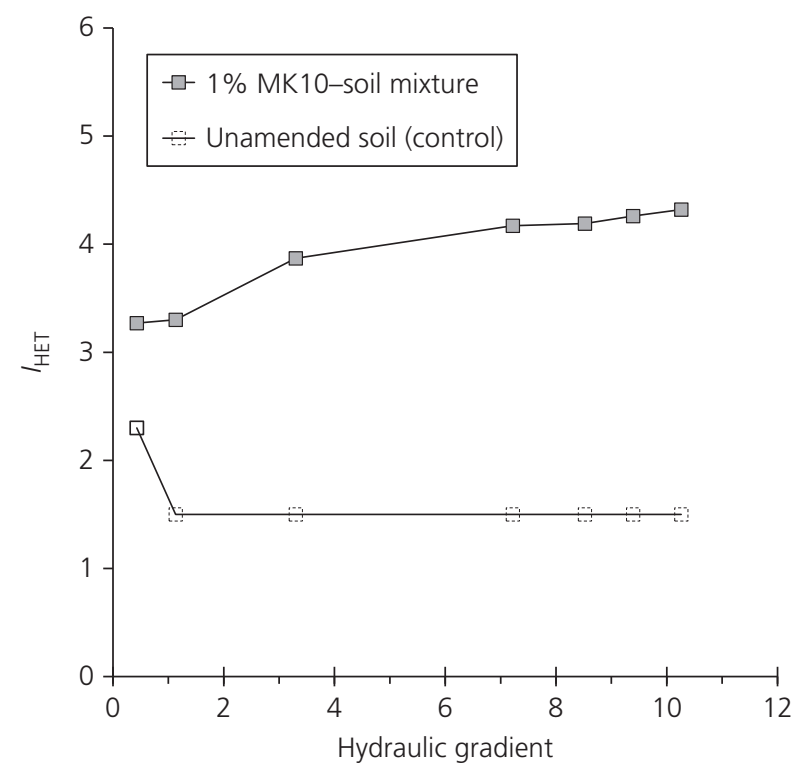

Figure 9. Effect of hydraulic gradient on erosion rate index and critical shear stress for 1\% MK10-soil specimens SP compacted at $12 \cdot 8 \%$ water content 
the SP-compacted unamended soil was categorised as HET group 1 or 2 material (i.e. $I_{\mathrm{HET}}=1-2$ ), with an $I_{\mathrm{HET}}$ value of 1.5 assigned in presenting their data for $i=1 \cdot 13-10 \cdot 3$ in Figure 9.

Bendahmane et al. (2008) reported that erosion occurs on account of suffusion of the clay fraction for low hydraulic gradients and backward erosion of the sand fraction for high hydraulic gradients, with the extent of the erosion dependent on the clay content. In other words, for the modest and high hydraulic gradient tests performed in this investigation, backward erosion of the sand grains in the unamended soil specimens caused significantly more erosion to occur, which ruptured these specimens within a few minutes of starting the HETs. Referring to Figure 9, the 1\% MK10-soil mixture, by contrast, was found to experience a marginal increase in erosion resistance for increasing hydraulic gradient, from which it is postulated that the MK10 additive counteracts backward erosion of the sand grains.

\subsubsection{Optimum MK10 content for erosion control}

Referring to Figure 6, for the 0.5-6\% MK10-soil mixtures investigated, the $6 \%$ MK10 content produced the greater erosion resistance, but considering the significant financial cost of this additive, the $1 \%$ MK10 content is identified as the optimum mix design in terms of erosion resistance improvement for the SP-compacted very silty sand investigated. This generally agrees with the $2 \%$ MK10 content identified by Tabarsa et al. (2018) from a pilot field stabilisation study of vibratory-plate compacted natural loess soils at one of the main irrigation channels of Gonbad Dam, north-eastern Iran. Whereas prepared MK10 suspensions were added to the dry test soil which was then thoroughly mixed for this investigation, Tabarsa et al. (2018) took a different approach, adding the MK10 powder material at various concentrations to the natural soil in-situ. It is the authors' opinion that the approach adopted in this investigation produces a more homogeneous distribution of the MK10 additive in the soil matrix.

\subsection{Performance comparison of MK10 and cement additives}

Table 4 lists the $I_{\mathrm{HET}}$ results for the $0 \cdot 25-3 \cdot 0 \%$ cement (C)-soil mixtures which were tested in triplicate. An initial observation from this table is that for a given cement content and curing period, the $I_{\mathrm{HET}}$ results obtained for the three replicates again confirm that inherent variability of the experimental HET approach was small. Figure 10 compares the mean $I_{\mathrm{HET}}$ values obtained for the SP-compacted test soil mixed with $0 \cdot 5-1 \cdot 5 \%$ MK10 and $0 \cdot 25-3 \cdot 0 \%$ cement, investigating curing periods of between 1 and $28 \mathrm{~d}$. Overall, and comparing similar dry weight additions, the soil-cement mixtures performed marginally better than the soil-MK10 mixtures, with the $I_{\mathrm{HET}}$ values rising by $12-16 \%$ with increasing curing period from 1 to $28 \mathrm{~d}$

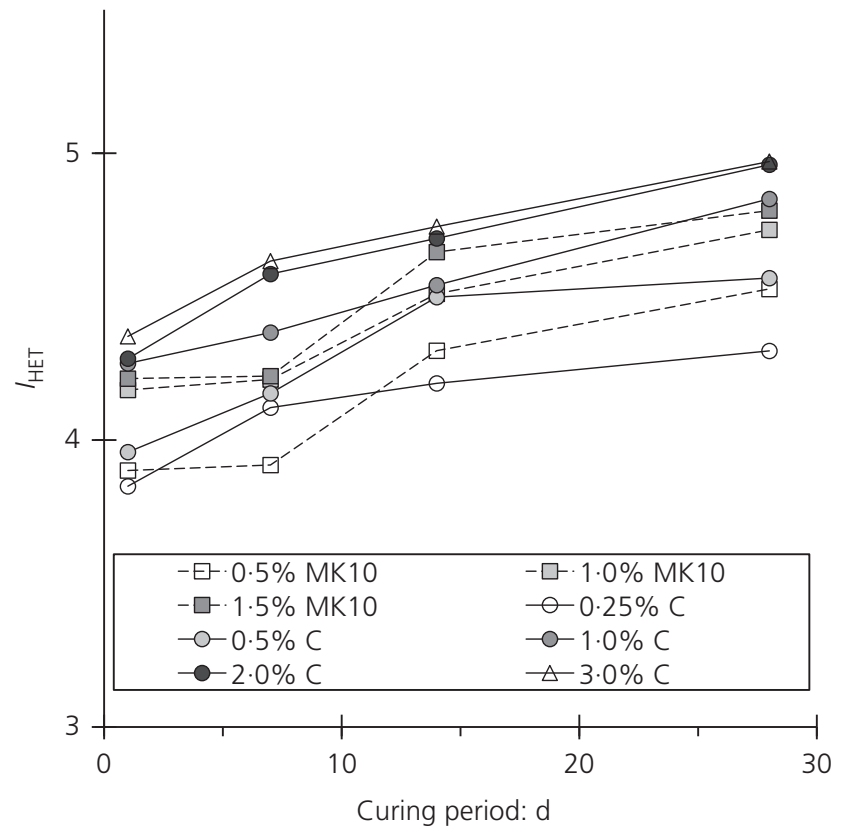

Figure 10. Comparison of MK10 and cement (C) additives in improving the hydraulic erosion resistance of the SP-compacted test soil

for $w=12 \cdot 8 \%$ and $i=7 \cdot 2$ investigated. For instance, the 28-d $I_{\text {HET }}$ values achieved for $1 \%$ MK10 and $1 \% \mathrm{C}$ additions were 4.73 and 4.84 , respectively. Again, referring to Figure 10: it is notable that all additive concentrations investigated achieve an $I_{\mathrm{HET}}>4$ (moderately slow erosion classification) for one-day curing, apart from $0 \cdot 25 \% \mathrm{C}, 0 \cdot 5 \% \mathrm{C}$ and $0 \cdot 5 \%$ MK10 additions (moderately rapid erosion), although this was rectified within $7 \mathrm{~d}(0 \cdot 25 \% \mathrm{C}$ and $0 \cdot 5 \% \mathrm{C})$ and $14 \mathrm{~d}(0 \cdot 5 \% \mathrm{MK} 10)$ curing periods.

\section{Recommendations for future investigations}

Further laboratory testing along with pilot field studies are recommended to corroborate the presented HET results, as well as investigating the impacts of in-situ mixing procedures and larger hydraulic gradients on the presented findings. This could include performing other soil erodibility testing approaches, such as furrow erosion, jet erosion (US BoR and ACE, 2015; Wahl et al., 2008) or surface-stream tests (Tabarsa et al., 2018). In addition, future investigations could compare the erosion resistance improvement achieved for MK10 addition with other traditional additives, like lime and fly ash. Further, commercial MK10 material is acidic (cationic), such that geo-environmental and geohydrology impacts of its mass mixing with the in-situ soil and on the groundwater $\mathrm{pH}$ must be carefully considered (Johnston and O'Kelly, 2016). 


\section{Summary and conclusions}

The results of the HET testing programme demonstrated at bench scale the feasibility of achieving substantial improvements in hydraulic erosion resistance of highly erodible SP compacted, very silty sand using very small additions of MK10 additive. Compared to cement stabilisation, the MK10 additive is equally effective at similar dry weight concentrations, but with the advantage of presumably substantially lower embodied carbon. Based on the presented HET results, the $1 \%$ MK10-soil mixture (mean $I_{\mathrm{HET}}=4 \cdot 1$ for $i=3 \cdot 3-10 \cdot 3$ indicating its moderately strong erosion resistance) was identified as the optimum performing mixture for the $0 \cdot 5-6 \%$ MK10 content range investigated. Further, the erosionresistance-group classification for SP-compacted 1\% MK10 soil specimens was not affected for under-compaction that produced a dry density of $0.8 \times \mathrm{SP} \rho_{\mathrm{d} \text { max }}$, or for compaction at the lower limit of the typically allowable moulding water content range of $w_{\text {opt }} \pm 2 \%$, or for widely different applied hydraulic gradients in the range of $i=0 \cdot 43-10 \cdot 3$ investigated. As expected, marginally greater erosion resistance was achieved for higher compaction (dry density) levels, higher moulding water contents within the allowable compaction water content range, longer curing periods and apparently also for higher hydraulic gradient values.

\section{Acknowledgement}

The authors thank the anonymous peer reviewers for many helpful queries on the original submission that greatly aided in improving the final paper.

\section{REFERENCES}

Amin M, Zomorodian SMA and O'Kelly BC (2017) Reducing the hydraulic erosion of sand using microbial-induced carbonate precipitation. Proceedings of the Institution of Civil Engineers Ground Improvement 170(2): 112-122, https://doi.org/10.1680/ jgrim.16.00028.

Aminpour M and O'Kelly BC (2015) Applications of biopolymers in dam construction and operation activities. In Proceedings of the Second International Dam World Conference, Lisbon, Portugal (Pina C, Portela E, Caldeira L, Batista A, Dias I and Santos R (eds)). Laboratório Nacional de Engenharia Civil, Lisbon, Portugal, vol. 1, pp. 937-946.

Arabani M, Haghi AK, Mohammadzade Sani A and Kamboozia N (2012) Use of nanoclay for improvement the microstructure and mechanical properties of soil stabilized by cement. In Proceedings of the Fourth International Conference on Nanostructures (ICNS4), Kish Island, Iran. Institute for Nanoscience and Nanotechnology, Sharif University of Technology, Sharif, Iran, pp. 1552-1554.

Bahari M and Shahnazari A (2015) Experimental study of the fine-grained earthen bed stabilization using nanoclay. Water and Soil Science 19(72): 107-114.

Benahmed N and Bonelli S (2012) Investigating concentrated leak erosion behaviour of cohesive soils by performing hole erosion tests. European Journal of Environmental and Civil Engineering 16(1): 43-58, https://doi.org/10.1080/19648189.2012.667667.
Bendahmane F, Marot D and Alexis A (2008) Experimental parametric study of suffusion and backward erosion. Geotechnical and Geoenvironmental Engineering 134(1): 57-67, https:/doi.org/ 10.1061/(ASCE)1090-0241(2008)134:1(57).

BSI (British Standards Institution) (1990) BS 1377-4: Methods of test for soils for civil engineering purposes (compaction-related tests). BSI, London, UK.

BSI (2015) BS 5930: Code of practice for ground investigations. BSI, London, UK.

Day RW (2001) Soil Testing Manual. McGraw-Hill, New York, NY.

EC (European Commission) (2019) Regulation (EC) No 1272/2008 of the European Parliament and of the Council of 16 December 2008 on Classification, Labelling and Packaging of Substances and Mixtures. EC, Luxembourg, See https://eur-lex.europa.eu/legalcontent/EN/TXT/?uri=CELEX:02008R1272-20190726 (accessed 18/11/2019).

Foster M, Fell R and Spannagle M (2000) The statistics of embankment dam failures and accidents. Canadian Geotechnical Journal 37(5): 1000-1024.

Garzón E, Cano M, O’Kelly BC and Sánchez-Soto PJ (2015) Phyllite clay-cement composites having improved engineering properties and material applications. Applied Clay Science 114: 229-233, https://doi.org/10.1016/j.clay.2015.06.006.

Garzón E, Cano M, O’Kelly BC and Sánchez-Soto PJ (2016) Effect of lime on stabilization of phyllite clays. Applied Clay Science 123: 329-334, https://doi.org/10.1016/j.clay.2016.01.042.

Huang Y and Wang L (2016) Experimental studies on nanomaterials for soil improvement: a review. Environmental Earth Sciences 75(6): 497, https://doi.org/10.1007/s12665-015-5118-8.

Indraratna B, Athukorala R and Vinod J (2013) Estimating the rate of erosion of a silty sand treated with lignosulfonate. Geotechnical and Geoenvironmental Engineering 139(5): 701-714, https://doi.org/10.1061/(ASCE)GT.19435606.0000766

Johnston PM and O'Kelly BC (2016) Importance of environmental geotechnics. Environmental Geotechnics 3(6): 356-358, https://doi.org/10.1680/envgeo.13.00123.

Kananizadeh N, Ebadi T, Rizi SEM and Khoshniat SA (2011) Behavior of nanoclay as an additive in order to reduce Kahrizak landfill clay permeability. In Proceedings of the Second International Conference on Enviromental Science and Technology. IACSIT Press, Singapore, vol. 6, pp. 55-59.

Khatami HR and O'Kelly BC (2013) Improving mechanical properties of sand using biopolymers. Geotechnical and Geoenvironmental Engineering 139(8): 1402-1406, https://doi.org/10.1061/ (ASCE)GT.1943-5606.0000861.

Khatami H and O'Kelly BC (2018) Prevention of bleeding of particulate grouts using biopolymers. Construction and Building Materials 192: 202-209, https://doi.org/10.1016/j.conbuildmat.2018.10.131.

Lim SS (2006) Experimental Investigation of Erosion in Variably Saturated Clay Soils. PhD thesis, University of New South Wales, Sydney, Australia, See http://handle.unsw.edu.au/1959.4/26159 (accessed 12/11/2019).

Majeed ZH and Taha MR (2012) Effect of nanomaterial treatment on geotechnical properties of a Penang soft soil. Asian Scientific Research 2(11): 587-592.

Majeed ZH, Taha MR and Jawad IT (2014) Stabilization of soft soil using nanomaterials. Applied Sciences, Engineering and Technology 8(4): 503-509, https://doi.org/10.19026/rjaset.8.999.

Merck (Merck KGaA) (2019) Nanomaterials. Merck KGaA, Darmstadt, Germany. See https://www.sigmaaldrich.com/materials-science/ material-science-products.html?TablePage $=9539469$ (accessed 14/11/2019). 
Neethu SV and Remya S (2013) Engineering behaviour of nanoclay stabilized soil. In Proceedings of the Indian Geotechnical Conference: Geotechnical Advances and Novel Geomechanical Application, Roorkee, India.

Padidar M, Jalalian A, Abdouss M et al. (2014) Effect of nanoclay on soil erosion control. In Proceedings of the Sixth International Conference on Nanomaterials - Research and Application (NANOCON2014), Brno, Czech Republic. 4pp, See http://nanocon2014.tanger.cz/files/proceedings/20/reports/3533.pdf (accessed 12/11/2019).

Shahrokhi-Shahraki R, Zomorodian SMA, Niazi A and O'Kelly BC (2015) Improving sand with microbial-induced carbonate precipitation. Proceedings of the Institution of Civil Engineers - Ground Improvement 168(3): 217-230, https://doi.org/10.1680/ grim.14.00001.

Sherard JL (1953) Influence of Soil Properties and Construction Methods on the Performance of Homogeneous Earth Dams. PhD thesis, Harvard University, Cambridge, MA, USA

Tabarsa A, Latifi N, Meehan CL and Manahiloh KN (2018) Laboratory investigation and field evaluation of loess improvement using nanoclay - a sustainable material for construction. Construction and Building Materials 158: 454-463, https://oi.org/10.1016/ j.conbuildmat.2017.09.096.

Taha MR and Taha OME (2012) Influence of nano-material on the expansive and shrinkage soil behavior. Nanoparticle Research 14(10): 1190, https://doi.org/10.1007/s11051-012-1190-0.

US BoR and ACE (US Bureau of Reclamation and US Army Corps of Engineers) (2015) Chapter IV-4: Internal erosion risks for embankments and foundations. In Best Practices in Dam and Levee Safety Risk Analysis, Version 4.0. US Department of the Interior, Bureau of Reclamation and US Army Corps of Engineers, See https://www.usbr. gov/ssle/damsafety/risk/BestPractices/Chapters/IV-4-20150617.pdf (accessed 12/11/2019).

Wahl TL, Regazzoni PL and Erdogan Z (2008) Determining Erosion Indices of Cohesive Soils with the Hole Erosion Test and Jet Erosion Test. US Department of the Interior, Bureau of Reclamation, Denver, CO, USA, Report DSO-08-05, See https://www.usbr.gov/research/projects/download_product.cfm?id= 298 (accessed 12/11/2019).
Wan CF and Fell R (2002) Investigation of Internal Erosion and Piping of Soils in Embankment Dams by the Slot Erosion Test and the Hole Erosion Test, July 2002. University of New South Wales, Sydney, Australia, Report number UNICIV-R-412.

Wan CF and Fell R (2004a) Investigation of rate of erosion of soils in embankment dams. Geotechnical and Geoenvironmental Engineering 130(4): 373-380, https://doi.org/10.1061/ (ASCE)1090-0241(2004)130:4(373).

Wan CF and Fell R (2004b) Laboratory tests on the rate of piping erosion of soils in embankment dams. Geotechnical Testing Journal 27(3): 295-303, https://doi.org/10.1520/GTJ11903.

Zhang G (2007) Soil nanoparticles and their influence on engineering properties of soils. In Proceedings Geo-Denver 2007: Advances in Measurement and Modeling of Soil Behavior, Denver, CO, USA (DeGroot DJ, Vipulanandan C, Yamamuro JA, Kaliakin VN, Lade PV, Zeghal M, El Shamy U, Lu N and Song CR (eds)). ASCE, Reston, VA, USA, GSP 173, pp. 1-13, https://doi.org/ $10.1061 / 40917(236) 37$.

Zhang G, Germaine JT, Whittle AJ and Ladd CC (2004) Index properties of a highly weathered old alluvium. Géotechnique 54(7): 441-451, https://doi.org/10.1680/geot.2004.54.7.441.

Zomorodian SMA and Koohpeyma HR (2015) Investigation of effectiveness of modern chemical stabilizers on internal erosion in embankment dams. Sharif Journal of Civil Engineering 30-2(4.2): 73-78.

Zomorodian SMA, Shabnam M, Armina S and O'Kelly BC (2017) Strength enhancement of clean and kerosene-contaminated sandy lean clay using nanoclay and nanosilica as additives. Applied Clay Science 140: 140-147, https://doi.org/10.1016/j.clay. 2017.02.004.

Zomorodian SMA, Ghaffari H and O'Kelly BC (2019a) Stabilisation of crustal sand layer using biocementation technique for wind erosion control. Aeolian Research 40: 34-41, https://doi.org/10.1016/ j.aeolia.2019.06.001.

Zomorodian SMA, Soleymani A and O'Kelly BC (2019b) Briefing: improving erosion resistance of sand using nano-silica additive. Proceedings of the Institution of Civil Engineers Ground Improvement 172(1): 3-11, https://doi.org/10.1680/ jgrim.17.00086.

\section{How can you contribute?}

To discuss this paper, please email up to 500 words to the editor at editor@britishdams.org. Your contribution will be forwarded to the author(s) for a reply and, if considered appropriate by the editorial board, it will be published as discussion in a future issue of the journal. 